\title{
Learning the Red Lines
}

\begin{abstract}
In this chapter we, as scholars of authoritarianism, discuss the 'red lines', a term used in authoritarian contexts to denote topics that are highly politically sensitive. We first describe commonalities in what the red lines are in different contexts, distinguishing between hard red lines and more fluid ones. We describe how we navigate red lines in fieldwork by offering a depoliticized, but not untrue, version of our research; how we adapt our wording and behavior to remain within the red lines, but still give us meaningful research results; and how we respond when the red lines shift, and words and behaviors previously acceptable become taboo, or vice versa.
\end{abstract}

Keywords Authoritarianism - Field research • Red lines • Sensitive topics

Observers of Chinese politics use the term 'red lines' to denote topics that are highly politically sensitive, the idea being that these are lines that must not be crossed. A red line does not necessarily mean that a topic cannot be discussed at all, but great care must be taken how it is discussed, and with whom. The term 'red lines' is also used in Morocco, and in Farsi there is also such an expression. In other contexts, we have not come across the phrase as such, but we adopt it here as a useful shorthand for topics or issues that are sensitive in the sense that investigating them is considered

(C) The Author(s) 2018

M. Glasius et al., Research, Ethics and Risk in the Authoritarian Field, https://doi.org/10.1007/978-3-319-68966-1_3 
threatening or forbidden by the regime (see also Ahram and Goode 2016, 840 ). Thus, our notion of 'red lines' is distinctly political. We do not discuss primarily cultural dimensions of what constitutes appropriate or inappropriate topics and behaviors. Of course a field researcher also needs to be aware of cultural taboos but that is not a matter restricted to authoritarian contexts.

In this chapter, we first describe what we know of what the red lines are in different contexts. We distinguish between hard red lines and more fluid ones. With respect to the hard red lines, we find considerable commonalities across countries. For us as scholars of authoritarianism, understanding the red lines is our bread and butter, but we believe it is important for any professional visitor to an authoritarian-ruled state to at least gain an understanding of the hard red lines. The fluid lines are much more contextspecific, more dependent on who we are interacting with, and more subject to change over time. The main commonality here is this ambiguity itself, which keeps us in uncertainty about precisely what is permissible.

We devote the bulk of the chapter to discussing how we navigate the red lines. Our primary strategy, and that of others, has been to be open and honest about the fact that we are social science researchers, and to explain the nature of our research in terms that are approximately accurate, but stripped of their politically sensitive import, so as to stay within the red lines. We give many examples, from our own experience and that of others, to elucidate what we mean by a 'depoliticized version' of our research, giving special attention to the wordings we use, and how local contacts can help us adapt our wording. We also give some examples of behaviors that, while far from being outrageous, came close to or crossed the red lines. Finally, we devote some attention to how the shifting of red lines over time can affect research.

\section{HARd Red Lines}

While the hard red lines are taboo subjects, it is not particularly difficult to discover, even before entering the field, what they are. What they have in common is that they are directly connected to regime stability, or the regime's core legitimizing narrative. In Iran, it is always the Supreme Leader: you cannot criticize him or question his position. In Morocco, likewise, his Majesty the King is a red line topic, and in Kazakhstan, it is the President who has been head of state for the last 28 years. In China, members of the Politburo Standing Committee can never be criticized. 
Corruption is an important political topic in many of the contexts we investigate, and it is not necessarily controversial to discuss corruption as a societal problem. But investigating corruption in relation to the current top-level leadership is almost always taboo. This is true for the top leadership of the Chinese Communist Party and for the Iranian Revolutionary Guard. There is ample evidence of how sensitive investigating top-level corruption in authoritarian contexts is and of how regimes respond to it. An investigation by The New York Times journalists on the wealth of then Chinese prime minister Wen Jiabao's family resulted in the blocking of the newspaper's website in China (Barboza 2012; Branigan 2012). In Malaysia, a deputy public prosecutor was killed after investigating a corruption scandal in which the prime minister was embroiled, and allegedly leaking information about the case to the press (Sarawak Report 2015). In a decentralized country like Mexico, certain states are notorious for attacks on journalists who investigate the involvement of state-level officials in corruption scandals. None of us has done field research on the authoritarianism-corruption nexus, and we know relatively few academics who do so. A recent book that does focus on the nefarious financial networks of Central Asian leaders relies primarily on desk research (Cooley and Heathershaw 2017, 20-22), especially from court cases, leaked documents, and NGO sources.

Two other common red lines are ethnic or religious cleavages in society, and occupied or secessionist territories. These issues are red lines because openly discussing them can put into question the societal and/or territorial cohesion of the authoritarian state. In Malaysia, the 'special rights' of Malays in relation to primarily Chinese and Indian minorities are a red line and cannot be questioned. On the one hand the government exploits the fears and tensions between the different groups to some extent, positing itself as the guarantor of peaceful relations; on the other hand, it may genuinely fear large-scale ethnic unrest, as well as Islamic radicalism. In Kazakhstan discussing ethnic relations is problematic, unless framed in terms of the official discourse of harmony and tolerance. In China, focusing on conflicts between the Uyghur minority and other ethnic groups is unacceptable. In Rwanda, as reported by Loyle $(2016,925)$, asking questions about a person's ethnic identity is actually proscribed by law. Questioning Morocco's sovereignty over the Western Sahara, or suggesting that the rights of the local population are being violated, is a red line for Morocco, as is questioning whether Tibet or Taiwan belongs to China in the Chinese context (see also Reny 2016,916). 


\section{FLUID LiNES}

Beyond the hard red lines, it is clear who is in power, but it is never certain what exactly is possible. As Loyle $(2016,924)$ writes about Rwanda, authoritarian regimes create 'a gray area around certain research topics. Restrictions are vague and punishments appear random. As a result, scholars may be unclear about what is or is not permitted and confused about the potential consequences of asking different types of research questions'. There is always a margin of error. Citizens of authoritarian countries, especially those who operate in political contexts, whether they are officials, critics, academics or students, corporate executives, or journalists, carefully assess their navigation of the fluid lines. If they cross them, even in a private, anonymous interview with a foreign scholar, they will not be doing so unwittingly. Local journalists in particular consider the red lines every day. For them, the lines are different, more restrictive, than for us, because what they write or say is read or heard by a broad local audience immediately, rather than by a narrow English-speaking academic audience, many months later. They can be a good source for us precisely because they may sometimes want to express to us privately what they know but cannot communicate openly in their own work.

A fluid line, for instance, is the degree to which government institutions and politicians below the leadership can be discussed and criticized. In Kazakhstan, there is some, and in China, Malaysia, and Morocco, even considerable leeway to critically discuss and investigate specific ministries, local authorities, or government policies. Intra-elite rivalries sometimes increase the space for sensitive research, but there can also be a danger of getting caught up in them: in Iran, for instance, contact with westerners can in itself be the subject of intra-elite mistrust and slander.

Likewise, there is great variation in the degree to which antigovernmental activism is sensitive. In Iran, the topic of political prisoners is a red line, as is the Green Movement to some extent. In Malaysia, the main protest movement campaigning for clean and fair elections, Bersih, operates quite openly. Today, while not everyone feels comfortable participating in the protests, discussing them is not experienced as problematic. But the religious and ethnically based anti-governmental Hindu movement ('HINDRAF') is much less openly tolerated and a more sensitive topic of discussion. In China too, the degree to which one can discuss protests publicly really depends on topic and context. Our China researcher found her online posting of information on protests in Hong Kong 
censored; but when she posted or forwarded international news coverage of a mass protest against a proposed factory in Northeast China, nothing was blocked. We can approach these differences analytically, thinking of reasons why a minority movement is more sensitive than a cross-ethnic movement, or why Hong Kong is more of a red line than a local protest in the far north, but we also believe that when it comes to the fluid lines, distinctions can be more arbitrary and do not always lend themselves to logical explanation.

\section{Depoliticizing the Research}

One of the clearest, most commonly agreed recommendations in the emerging literature on fieldwork in authoritarian circumstances is to 'frame the research topic in a way that has the best chance of reducing any sensitivity around it' (Art 2016, 980). This appears to be a common practice among scholars of the post-Soviet region, as reported in the Central Eurasian Studies Society's recent task force report on fieldwork safety. According to their survey, ' $(\mathrm{m})$ any respondents admitted to adjusting the presentation of their research topic to decrease risk. Some respondents indicated that they either do not disclose their real research topics to anyone or change how they describe their work depending on the context, whether a government institution, university, etc.' (CESS 2016, 6). The report also mentions that a 'small minority reports outright misrepresenting their purpose for being in-country, a practice that we [the taskforce] find ill-advised' (CESS 2016, 7) because of the risk it poses to local helpers after publication of the real research. Making research sound 'bland and gray', avoiding 'phrases that hint at political curiosity or other sensitive topics' (Turner 2013, 398) is apparently also a usual approach to field research in socialist East Asian states including China, Laos, and Vietnam (Cornet 2013; Petit 2013; Sowerwine 2013, all cited in Turner 2013; Reny 2016). Country specialists on Iran (Malekzadeh 2016), Kazakhstan (Gentile 2013), and Rwanda (Loyle 2016) all refer to similar strategies. While most accounts recommend depoliticizing research for pragmatic reasons such as gaining access and reducing risk, Malekzadeh $(2016,866)$ adds the important insight that an interest in the mundane may actually improve research validity. While initially 'looking for dramatic or expressed bursts of opposition or bouts of justice seeking under authoritarian rule', he learned instead to seek out 'how people negotiate with what can be a suffocatingly tedious and impenetrable bureaucratic setting in order to 
improve their own lives'. This chimes with Pepinsky's (2017) plea for attention, in the Malaysian context, to 'everyday authoritarianism' rather than looking for spectacular repression.

Just like these other scholars in the authoritarian field, we do not tell lies about what our research is about, and we do present our plans in ways that are neutral, non-specific, and depoliticized. But depoliticizing political science research is easier said than done. Below, we elaborate on our own practices and the examples given by others in order to give practical substance to what it means to 'make it boring' (Malekzadeh 2016, 865).

First, there is the term 'authoritarianism' itself. The common research project that we mainly draw on for this book is called 'authoritarianism in a global age'. It is no secret that we investigate authoritarianism. If you google any of us, you will come across the term, and it is likely that all our publications, some more prominently than others, will feature the term 'authoritarian'. In China, interestingly, authoritarianism itself is not a red line, or at least until recently it was not. Government officials do not themselves refer to the regime as authoritarian, but foreign and even domestic scholars openly do so in conversation, if not in Chinese publications. It is not considered a term of opprobrium, just an analytical distinction from democracy. In Morocco by contrast, where the regime likes to see itself described as 'democratizing', authoritarian as an adjective applied to the Kingdom is a red line.

But regardless, in explaining what we do during fieldwork, most of us never use it. It is not even that it would necessarily be dangerous to do so, it is just unhelpful. Speaking of authoritarianism (or democracy for that matter) invites abstract discussions about ideologies, cultural differences, or western hypocrisy. Some respondents might react badly to the suggestion that their government is authoritarian; others, especially activists, might actually embrace it. Either way such discussions often lead us away from the concrete things we want to find out. We might refer to the general project as being about comparing different state responses to globalization, and then go on to describe our specific research interest.

Our Chinese researcher when introducing herself, especially to officials, gives them her business card-which has her name and affiliation in Chinese and English, but not the name of our project (see also Loyle 2016, 929 and Malekzadeh 2016, 867 on business cards as symbols of the legitimacy of our status as researchers). She gives them many details, lots of answers to any questions they may have, so they are not left with the feeling that she is hiding anything. In her recent research on the interactions 
between Chinese companies and government agencies over big data, she would not mention concerns about privacy, surveillance, or censorship. Instead, she would refer to US companies and government-corporate relations to initiate conversations. Taking the United States both as a competitor and point of reference allowed government officials as well as company managers to talk easily about the Chinese situation.

Our Iran researcher, when interested in online censorship, surveillance, and harassment by the Iranian authorities, framed this as an interest in Iran's Internet policies, or recent developments regarding the Internet in Iran. Even in interviews with activists, he would not introduce the term 'censorship' into a conversation himself but follow the lead of a respondent in terms of the wording and the depth of discussion.

Loyle, in the context of Rwanda, also gives some very concrete examples of how to depoliticize research topics: 'it may be unwise (or prohibited) to ask questions about government corruption in distributing natural resource contracts but alternate wording of the research question, such as "contract allocation" or "indicators of governance effectiveness," can provide similar answers without drawing unwanted attention to your research. Concepts such as "state violence" or "repression" can easily be replaced with words such as "conflict" to suggest general patterns of violence instead of research directed toward abuses by the state' (Loyle 2016, 930).

Sometimes, with a particular type of respondents, we find that there are advantages to dropping the depoliticized version that we crafted. Our Malaysia researcher, after initially being cautious, discovered that much more could be discussed openly than he expected, and it worked to be very forthright. He began to introduce himself to activists as doing research on Internet and protests in authoritarian regimes-usually adding that it was debatable how authoritarian Malaysia was. This was also the experience of our researcher on the subnational contexts of India and Mexico. He found that using the word 'authoritarian', which is not exactly commonplace in these formally democratic states, was actually helpful when speaking to local opposition figures and journalists. These illustrations just go to show how context-dependent the appropriate ways and degrees of depoliticizing one's research are. In most other authoritarian contexts, such an opening would be most alarming to respondents and kill any chance of a good interview. But in these specific contexts, with this particular group of respondents, it was actually an icebreaker. 


\section{WORDING}

Knowing the red lines is not just a matter of knowing what can be discussed but also how to discuss it and with whom. In referring to the various heads of state above, we instinctively remained within the red lines: to refer to the Supreme Leader or his Majesty the King as plain Khamenei or Mohammad VI would be disrespectful. Not dangerous, but inappropriate and therefore unhelpful, especially in conversations with officials, but sometimes also with ordinary people. We have learned this by listening carefully, in formal and informal conversations, to how locals spoke of their leaders.

Just as there are appropriate and inappropriate forms for referring to the head of state, there may be commonly understood neutral terms for sensitive topics, as well as terms that raise alarm bells. Matelski found that in Myanmar before democratization, 'people often referred to "the situation" to describe the general conditions they had to live in under military rule without having to go into detail' (Matelski 2014, 64, 67). Many Iranians will refer to the Green Movement's large-scale post-election protests, and the subsequent regime repression of the movement, obliquely as 'the events of 2009'. Our Kazakhstan researcher found when she worked for the United Nations that, while many citizens engaged in what we would call volunteering, it was very difficult to find an acceptable vocabulary to talk about these activities. There are two words in Russian for 'volunteering'. The one with a Latin root (volonterstvo) was connected with the English-speaking world, foreign NGOs, and aid programs. People then reacted negatively to the notion of Kazakhstan as a third world country in need of foreign aid, and government accusations that foreign NGOs were 'importing' protest caused further suspicion. But her conversations fared no better with the other word for volunteering, which has a Slavic origin and was used in Soviet times for obligatory 'volunteering' for communist party-affiliated organs. How to talk about volunteering was not just a cultural or linguistic conundrum; it had political implications. From the government's perspective, the line between what is acceptable volunteering and what is not is very thin, revolving around the distinction between political and apolitical activities.

When speaking to officials, we sometimes adopt their discourse to some extent. Members of a constitutional reform commission in Morocco, for instance, were keen to describe the reform as a participatory process. Instead of questioning this, our researcher took up the notion of 
participation and asked to know more about who participated and how. Tailoring the wording of research to fit the preferences of respondents is not in itself unique: Art, for instance, described his research on radical right parties in Europe to party officials as an interest in parties 'very concerned with preserving the distinctive political and cultural values of their societies' (Art 2016, 981). What is distinctive about the authoritarian context in comparison is the element of risk involved (see Chap. 2), which can go well beyond being unfavorably received by potential respondents.

\section{Getting Locals to Vet Your Wording}

In case of doubt as to what wording of research questions may be more acceptable, while still conveying enough to elicit meaningful responses, the advice of trusted locals can be extremely helpful. When our Kazakhstan researcher first prepared for fieldwork, a diplomat turned researcher from the region helped her with the wording of letters to officials she wanted to interview, making the research sound harmless and interesting to them, and even flattering. Instead of asking after the authoritarian functions of the government party, he suggested she should ask officials how the party contributes to government effectiveness. Our Mexico researcher showed a human rights worker in the capital his list of proposed questions before traveling to the region, and was advised not to use the stark word 'repression', but speak of 'control' instead, or 'safeguarding information'. Reny describes the even more finely tailored advice she got from local collaborators in her research on underground churches in China. With pro-regime respondents, "(s)entences referring to house churches as "suppressed" (bei yazhi) or "controlled" (bei kongzhi) would automatically be replaced by "supervised" (bei guanli). These discursive subtleties would help reduce possibilities that interviewees interpreted my words as a critique' (Reny 2016, 919).

Having trusted local people consider one's wording is even more important when doing surveys. Contrary to what one might think, survey research is possible in authoritarian contexts-on some topics, in some countries. Three of us have conducted surveys. In survey research, one typically has no direct contact with one's respondents, no way of gauging their reactions and no chance to course correct. Surveys, moreover, leave an electronic or paper trail. Therefore, it is even more important than in 
face-to-face interviews to stay within the red lines, in terms of wording and topics. Our Malaysia researcher discovered that-while the political implications of ethnicity are in themselves a red line-it was considered crucial, in a telephone survey, that respondents were approached by interviewers of the same ethnicity, in their own language. Otherwise, he was told, respondents would not feel comfortable discussing political views or concerns at all. Our Kazakhstan researcher, despite extensive experience in the country, relied on local survey professionals to get her question about political activities phrased correctly. Our Chinese researcher ran her survey questions by some Chinese survey experts, and found that what she thought of as acceptable, neutral questions, relating to Chinese students' attitudes to democratic countries, or their views on the values of freedom or justice, could not be asked directly at all. The experts laughed and told her she had been abroad for too long.

\section{BEHAVIORS}

While most of our advice about navigating red lines revolves around choice of words, other forms of behavior too may be shaped and constrained by the 'red lines'. In the authoritarian field, a course of action that would appear completely natural in a less constrained context may entail a risk of exposing self or respondents. In the Chinese context, Reny $(2016,919)$ describes taking public transport with two missionaries for whom it might have been better not to be seen with her: '(b)y the time we got there, I realized we should have taken a taxi instead. Not only were we in a suburb where locals were not accustomed to seeing foreigners, but also we had to walk 10 minutes on the main street to reach their apartment ... (1)ocals on the street had enough time to notice me'. Our India researcher similarly found that he needed to course correct to avoid exposing respondents. Having gotten quite comfortable with the political setting after three months of fieldwork, he was conducting interviews in a coffee house wellknown to be frequented by left-wing activists, and hence-but he was not aware of this at the time-also by government agents. After firing off some sensitive questions about the Maoist insurgency, he was warned by one of his interlocutors: 'if I were you I would ask your questions a little bit more discreetly'. No difficulties ensued for respondents either in the Chinese public transport incident reported by Reny or in the Indian coffee house, but as always in these contexts, we constantly need to reflect on our behavior, because there might be consequences. 
Constant reflection on his own conduct, in relation to the 'red lines', was also the mode that our Malaysia researcher found himself in when attending an anti-government demonstration in 2016. Foreigners are not allowed to demonstrate, and his own embassy had advised against attending. Despite a bad experience during previous fieldwork (see Chap. 2), he decided, based on his own assessment and local advice, to go. During the demonstration he was continuously assessing whether to best be alone, or visibly part of a group; what he would do if anyone wanted to take a photo with him; what if anyone gave him the movement's yellow t-shirt to wear; what if the police would ask him what he was doing there. The demonstration, and his participation in it, passed without incident, but by the end of the day, he was exhausted by the constant self-assessment.

A very different fate befell Clotilde Reiss, a master's student who was in Isfahan, Iran, during the Green Movement protests in 2009, participated in the protests and took pictures, and apparently sent a brief report to the French research institute in Tehran (Ayad 2009). She was arrested and spent nearly a year in an Iranian prison. While our Iran researcher would think twice about giving information to western embassies and diplomats, especially by e-mail, reporting back to a research institute under these extraordinary circumstances is not a behavior beyond our comprehension. But in Iran, especially at that time, the accusation of 'spy' attached very easily to westerners, and she paid a heavy price. In terms of our behavior then, we sometimes walk a fine line between becoming overconfident and touching a red line, and being overcautious and sometimes a little paranoid. In Chap. 5 we will discuss the mental impact of such preoccupations in more detail.

\section{Shifting Red Lines-Closures}

The political fields we study do not stand still. Our China and our Kazakhstan researcher have both experienced that since they did their PhDs, there has come to be less scope for critical political discussion, whereas our Iran researcher has first witnessed a more liberal environment becoming very restricted and then again somewhat more relaxed in recent years. In China in recent years, the domestic academic climate has contracted. There used to be considerable leeway for-relatively abstractdiscussions about political values, such as the meaning of citizenship or the value of democracy, in university classrooms. Currently, it appears to be the case-although it is difficult to verify conclusively- that students are 
encouraged to report about what teachers tell them in the classroom, a practice that has not occurred since the Cultural Revolution. This directly impacts on what can be done during fieldwork. Previously, the accessibility of information directly from policy-makers might fluctuate, but academics were always an easy source of comments and analysis. Nowadays, it is getting increasingly difficult to talk with officials even with appropriate introductions (see next chapter), and even the utterances of academics depend on longstanding relations of trust. In Kazakhstan, the red lines have not so much shifted as hardened. In the years 2007-2011, the authorities were trying really hard to open up the system to respond to the requests of international organizations (the OSCE in particular, of which they were trying to get the chairmanship for 2010), which did have a liberalizing effect. Nowadays, both online and offline media appear to be more controlled, and there is less tolerance of dissent. In the more factionalized political environment of Iran, the supreme leader was always a red line, but since 2009, the institutions that harbor political hardliners, the Revolutionary Guard and the judiciary, have also become more sensitive as topics.

Beyond our own experiences, it is important to recognize that, while there may usually be a correlation between increasing authoritarian practices in a particular country and conditions for field research becoming more challenging, the two trends are analytically distinct and do not always move together. The Central Asia task force cited in the previous chapter, for instance, writes that 'many respondents commented on the increasing authoritarianism in Azerbaijan, but the threat is much more acute for citizens of the country than for foreigners', and appears not to have had a direct impact on the research environment so far (CESS 2016, 7).

\section{Shifting Red Lines-Openings}

In transition contexts by contrast, researchers have had the experience of finding their customary caution suddenly unnecessary, and actually a hindrance. One of us, a regular visitor to Egypt in the 2000s, interviewed a range of activists in Cairo when Morsi was president. While the situation was volatile, she found respondents utterly unrestrained in what they said and where they said it. One took her to a famous graffiti wall in a busy street near Tahrir Square and began, in broad daylight, to interpret the political imagery, pointing and speaking. The wall has since been destroyed, and such behavior would again be unthinkable today. Analogously, 
Matelski $(2014,72-73)$ relates how, working on civil society in Burma during the junta period, she had taught herself to speak in the idiom of oblique references that her respondents used. On a return visit after transition had been announced, she found that researchers new to the context 'did not seem as bothered by warnings and sensitivities and seemed able to discuss issues that I had been hesitant to bring up'. She attributed this discrepancy, not to 'oversensitivity on my part, or lack of context sensitivity on their part. It was simply the context that changed more quickly than any of us could have imagined'.

\section{Chapter Conclusion: Navigating the Red Lines}

We have tended to stay away from the hard red lines in our work on authoritarianism. We have been open about being political science researchers doing fieldwork. Perhaps there are circumstances in which it is both ethical and productive to act otherwise, but we find such circumstances difficult to imagine, and would be very reluctant to undertake 'undercover' research. Like others in the field, we do believe it is ethically justified, and mostly fruitful, to present our interests in a neutral and depoliticized light, as long as what we say is not beside the truth. We are professionals who have no sinister intent to destabilize the government. We present our research as analytically driven, perhaps a little technical and boring, and we strive to keep our behavior away from the red lines too. We typically err on the side of caution, especially in the early stages of our fieldwork, but sometimes find that we rapidly need to change gear to respond to unexpected openness.

\section{REFERENCES}

Ahram, A. I., \& Goode, J. P. (2016). Researching Authoritarianism in the Discipline of Democracy. Social Science Quarterly, 97, 834-849. https://doi. org/10.1111/ssqu.12340.

Art, D. (2016). Archivists and Adventurers: Research Strategies for Authoritarian Regimes of the Past and Present. Social Science Quarterly, 97, 974-990. https://doi.org/10.1111/ssqu.12348.

Ayad, C. (2009). Fin d'une longue captivite pour deux otages. Liberation. RetrievedJuly 20,2017,from http://www.liberation.fr/planete/2009/11/27/ fin-d-une-longue-captivite-pour-deux-otages_595967.

Barboza, D. (2012, November 24). Lobbying, a Windfall and a Leader's Family. New York Times. Retrieved July 20, 2017, from http://www.nytimes. 
com/2012/11/25/business/chinese-insurers-regulatory-win-benefits-a-leaders-family.html.

Branigan, T. (2012, October 26). New York Times Blocked by China After Report on Wealth of Wen Jiabao's Family. The Guardian. Retrieved July 20, 2017, from https://www.theguardian.com/world/2012/oct/26/new-york-timeschina-wen-jiabao.

Central Eurasian Studies Society (CESS). (2016, March 5). Taskforce on Fieldwork Safety. Final Report. Retrieved July 19, 2017, from http://www.centraleurasia.org/assets/site/cess-task-force-on-fieldwork-safety_final-reportmarch-2016.pdf.

Cooley, A., \& Heathershaw, J. (2017). Dictators Without Borders: Power and Money in Central Asia. New Haven and London: Yale University Press.

Gentile, M. (2013). Meeting the 'Organs': The Tacit Dilemma of Field Research in Authoritarian States. Area, 45, 426-432. https://doi.org/10.1111/ area. 12030 .

Loyle, C. E. (2016). Overcoming Research Obstacles in Hybrid Regimes: Lessons from Rwanda. Social Science Quarterly, 97, 923-935. https://doi. org/10.1111/ssqu.12346.

Malekzadeh, S. (2016). Paranoia and Perspective, or How I Learned to Stop Worrying and Start Loving Research in the Islamic Republic of Iran. Social Science Quarterly, 97, 862-875. https://doi.org/10.1111/ssqu.12342.

Matelski, M. (2014). On Sensitivity and Secrecy: How Foreign Researchers and Their Local Contacts in Myanmar Deal with Risk Under Authoritarian Rule. Journal of Burma Studies, 18, 59-82. https://doi.org/10.1353/jbs.2014.0008.

Pepinsky, T. (2017, January 6). Everyday Authoritarianism Is Boring and Tolerable. Retrieved July 21, 2017, from https://tompepinsky.com/2017/01/06/ everyday-authoritarianism-is-boring-and-tolerable/.

Reny, M. (2016). Authoritarianism as a Research Constraint: Political Scientists in China. Social Science Quarterly, 97, 909-922. https://doi.org/10.1111/ ssqu. 12345 .

Sarawak Report. (2015, November 25). Kevin Morais Drew Up The Charge Sheet Against Najib And Later Leaked It To Sarawak Report, Says Brother. Sarawak Report. Retrieved July 25,2017, from http://www.sarawakreport.org/2015/11/ kevin-morais-drew-up-the-charge-sheet-against-najib-and-then-sent-it-to-sarawak-report-says-brother/.

Turner, S. (2013). Red Stamps and Green Tea: Fieldwork Negotiations and Dilemmas in the Sino-Vietnamese Borderlands. Area, 45, 396-402. https:// doi.org/10.1111/area.12017. 
Open Access This chapter is licensed under the terms of the Creative Commons Attribution 4.0 International License (http://creativecommons.org/licenses/ by $/ 4.0 /$ ), which permits use, sharing, adaptation, distribution and reproduction in any medium or format, as long as you give appropriate credit to the original author(s) and the source, provide a link to the Creative Commons license and indicate if changes were made.

The images or other third party material in this chapter are included in the chapter's Creative Commons license, unless indicated otherwise in a credit line to the material. If material is not included in the chapter's Creative Commons license and your intended use is not permitted by statutory regulation or exceeds the permitted use, you will need to obtain permission directly from the copyright holder.

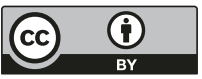

